\section{Las políticas públicas, el túnel subfluvial entre Paraná y Santa Fe y la integración física de la Megapotamia}

Maximiliano Camarda Medina

CONICET/Facultad de Ciencias Económicas, Universidad de Entre Ríos, Argentina

Jose Antonio Mateo Oviedo Correo

CONICET/ Facultad de Ciencias Económicas, Universidad de Entre Ríos, Argentina

Recibido: 28 de julio de 2017. Aceptado: 28 de septiembre de 2017.

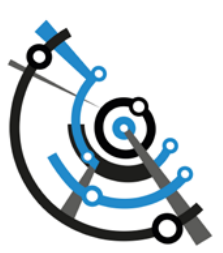

\title{
Resumen
}

En el presente trabajo nos proponemos analizar los diferentes momentos del proceso que devino en la construcción del túnel subfluvial que conectó la Provincia de Santa Fe y Entre Ríos, en el marco de políticas públicas que tuvieron una fuerte participación del Estado, con sus tensiones al interior, como así también de la sociedad y el mercado. Definimos a las políticas públicas como una relación entre actores (públicos y privados, afectados y beneficiados) que implica acciones para resolver un problema definido políticamente como público.

\section{Public policies, the sub-river tunnel between Paraná and Santa Fe and the physical integration of the Megapotamia}

\begin{abstract}
Abstrac
In the present work we propose to analyze the different moments of the process that became in the construction of the subfluvial tunnel which connected the Province of Santa Fe and Entre Rios, in the framework of public policies that had a strong participation of the State, with its tensions to the interior, as well as of society and the market. We define public policies as a relationship between actors (public and private, affected and benefited) that involves actions to solve a problem defined politically as public.
\end{abstract}

Palabras claves

Políticas públicas Túnel subfluvial

Estado

Federalismo

Palavras-chave

Política pública Túnel subfluvial Federalismo Estado

\section{Keywords}

Public policies River tunnel State Federalism

Si bien yo tengo algunas preferencias sobre como la política (policy) debe ser hecha, mi propósito inmediato es proveer un marco teórico o encuadre (framework) dentro del cual usted pueda analizar cómo la política es hecha. Luego de haber hecho esto usted estará en una mejor posición de determinar cómo las cosas deben funcionar (Jones 1977:9) 


\section{El marco del problema}

La mesopotamia argentina es, como su homónima de Oriente Próximo, un territorio de características insulares ubicado dentro de un continente. Algunos geógrafos la designan como Megapotamia, para evitar confundirla con la clásica oriental y para destacar la características gigantescas que tienen los ríos que circunscriben esta región comparados con el Tigris y el Éufrates (Difrieri, 1968). ${ }^{1}$

Desde al menos la ocupación colonial y hasta el presente, esta región en general y la provincia de Entre Ríos en particular (Schmit y Djenderedjian, 2008; Schmit, 2004) constituye un territorio con intensa presencia económica, social, política y cultural en la historia argentina. No obstante, tuvo durante siglos en sus grandes ríos una barrera natural que ralentizó el desplazamiento de información, personas y mercancías entre esta región y resto del continente. Este aislamiento y sus consecuencias para su desarrollo económico y social, la afectó tanto en su insularidad como en su relación con el resto de las provincias argentinas y con sus fronteras internacionales. En 1923, la empresa Ericsson instaló el primer enlace telefónico con la Megapotamia mediante la instalación de un cable subfluvial entre Santa Fe y Paraná (Reggini, 2012:78), pero el lento tránsito para conectar físicamente a las provincias megapotámicas con el resto del país o con sus países limítrofes recién comenzó a reducirse a principios del siglo $\mathrm{XX}$ con la utilización de vapores y balsas autopropulsadas que vinculaban el transporte carretero del continente con aquellas provincias o con los países vecinos de Brasil, Uruguay y Paraguay. Incluso al desarrollarse el ferrocarril en la región, el vínculo ferroviario debió recurrir a ferry-boats que transportaban sobre sus cubiertas locomotoras $\mathrm{y}$ vagones de una rivera a otra.

La primera conexión material entre la Megapotamia y el continente de inauguró oficialmente en 1947, -si bien los proyectos de conexión material son bastante anteriores a ese momento-, con el puente Paso de los Libres (Corrientes, Argentina)-Uruguaiana (Rio Grande do Sul, Brasil). ${ }^{2}$

El cruce entre las ciudades de Santa Fe (capital de la provincia homónima) y Paraná (capital de la provincia mesopotámica de Entre Ríos) se hacía regularmente, desde mediados del siglo XIX, con lanchas y vapores desde orillas del río Colastiné, primero hasta el Puerto Viejo de Paraná y luego hasta el Puerto Nuevo, desde su inauguración entre 1904 y 1907 (Musich, 2015).

Más de dos décadas después de inaugurado el puente internacional mencionado, a finales de 1969, se unió por primera vez a la Megapotamia con el resto de Argentina por carretera. A partir de ese año, la obra pública en infraestructura norteada en finalizar con el aislamiento de esta región, pasó de la escasez a la abundancia. La autoproclamada "Revolución Argentina" impulsó una serie de grandes obras de infraestructura vial y energética, la mitad de las cuales tuvieron lugar en la Megapotamia (Vitelli 1978). En efecto, la dictadura militar finalizó el casi paralizado Túnel Subfluvial e impulsó los puentes entre Barranqueras (Chaco) y la ciudad de Corrientes, Zárate (Buenos Aires) y Brazo Largo (Entre Ríos) (Ferrer y Rougier, 2010) y dos binacionales entre la provincia de Entre Ríos y la República Oriental del Uruguay (Puerto Unzué-Fray Bentos y Colón-Paysandú). Además, de las cuatro centrales hidroeléctricas emprendidas por esos años, una de ellas se construyó entre Salto y Concordia, cuyo coronamiento actúa como un tercer puente entre la provincia de Entre Ríos y Uruguay ${ }^{3}$. Estas obras se destacaron por su cantidad, su magnitud, su celeridad y su simultaneidad (Castellani, 2009).

En efecto, la cronología de obras inauguradas, indica la siguiente progresión, siguiendo la terminología habitual de las estructuras como se observa en el Cuadro 1.
1. Principalmente los ríos Paraná, Uruguay e Iguazú. Completan el perímetro los ríos San Antonio y Pepirí Guazú.

2. Entre los años 1934 y 1935 los presidentes Getulio Vargas y Agustín P. Justo acordaron la construcción de un puente ferroautomotor entre aquellas ciudades, que actualmente lleva sus nombres. El puente fue inaugurado oficialmente en mayo de 1947, durante las presidencias Perón-Dutra.

3. El resto, "El Chocón”, “Cerros Colorados" y "Futaleufú” fueron construidas en la Patagonia. 


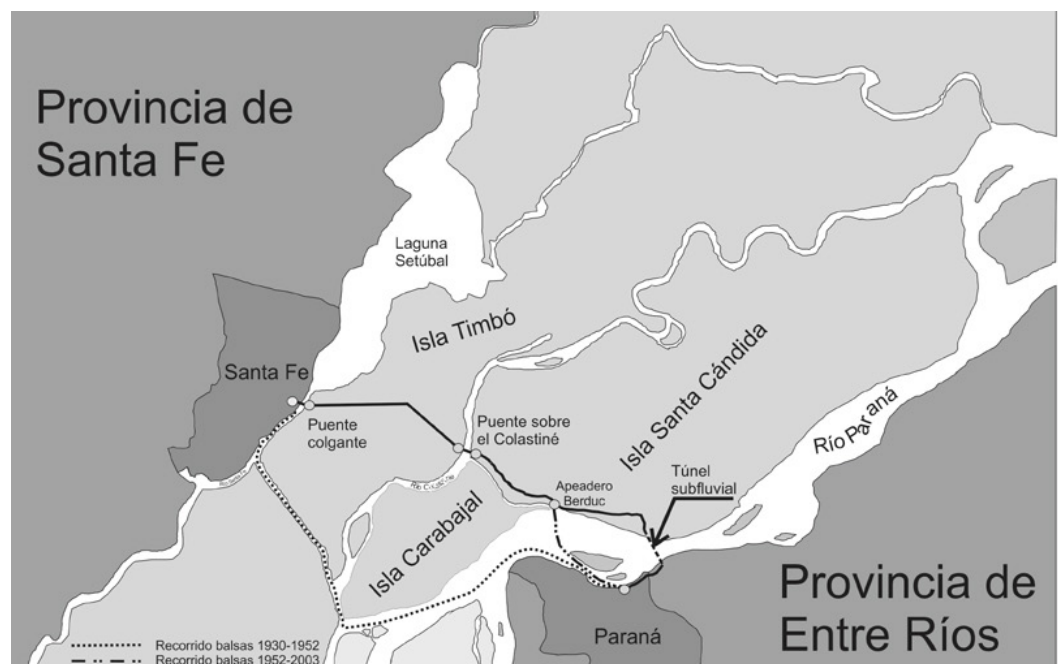

Cuadro 1. Obras de vinculación de la provincia de Entre Ríos con el continente (19691979). Fuente: Elaboración propia. Aclaración: a. Actualmente lleva el nombre de los ex gobernadores Raúl Uranga-Carlos Sylvestre Begnis; b. Aunque fue prevista su ampliación a ferroautomotor; c. Puente General Artigas; d. Puente General San Martín; c. Complejo Unión Nacional; $d$. Central Hidroeléctrica Binacional de Salto Grande; e. Coronamiento de la represa Salto Grande. El paso automotor se permite desde 1982.

\begin{tabular}{|l|c|c|c|c|}
\hline Obra & Tipo & Inicio & Inaugurado & Tipo \\
\hline Túnel subfluvial Hernandarias -a & Túnel carretero -b & 1962 & 1969 & Nacional (Santa Fe-Entre Ríos) \\
\hline Puente Colón-Paysandú -c & Puente carretero & 1973 & 1975 & $\begin{array}{c}\text { Binacional (Argentina- } \\
\text { Uruguay) }\end{array}$ \\
\hline Puente Puerto Unzué-Fray Bentos -d & Puente carretero & 1972 & 1976 & $\begin{array}{c}\text { Binacional (Argentina- } \\
\text { Uruguay) }\end{array}$ \\
\hline Complejo Zárate-Brazo Largo -e & Puente ferroautomotor & 1972 & 1977 & $\begin{array}{c}\text { Nacional (Buenos Aires-Entre } \\
\text { Ríos) }\end{array}$ \\
\hline Complejo Salto-Grande -f & $\begin{array}{c}\text { Central hidroeléctrica y } \\
\text { paso ferroautomotor -g }\end{array}$ & 1974 & 1979 & $\begin{array}{c}\text { Binacional (Argentina- } \\
\text { Uruguay) }\end{array}$ \\
\hline
\end{tabular}

La fecha de inauguración de las obras, sin dejar de ser de interés para los usuarios de cada sistema, no es más que un punto de inflexión en un proceso muy conocido en el ciclo de las políticas públicas. Esta fecha implicó al menos tres momentos: el de diagnóstico e inclusión en la "agenda pública" precedido de un extenso período de demandas hasta ser definido políticamente como "problema público" por el gobierno; el de diseño y elaboración del proyecto (que incluye a la licitación de las obras); y el de ejecución o implantación de la obra (que implica la adjudicación y su financiamiento, el ajuste al proyecto y una perenne negociación entre contratista y contratado). Post-facto, etapa que en muchas oportunidades no se ejecuta por diversos factores, es precisa la evaluación, es decir la contratación de los objetivos propuestos con las metas alcanzadas.

Nos proponemos en el presente trabajo analizar los diferentes momentos del proceso que devino en la construcción del túnel subfluvial en el marco de políticas públicas sustantivas que, si bien podemos calificarlas de estado-céntricas (Oszlak, 2014) por la fuerte participación del Estado en todos sus momentos, tuvieron papeles centrales tanto la sociedad y el mercado, e incluso enfrentó a diferentes fracciones del Estado. Las políticas públicas son, en esencia, una relación entre actores (públicos y privados, afectados y beneficiados) que implica acciones para resolver un problema definido políticamente como público.

Figura 1. Ubicación del túnel subfluvial. Fuente: Elaboración propia. 


\section{La historia y las políticas públicas}

No todo lo que hace el gobierno es política pública, pero no hay política pública que no tenga alguna participación del gobierno, y de éste emanan las autoridades políticoadministrativas, a las cuales les compete asumir ejecutivamente la resolución del problema público. Las políticas públicas -si hacemos abstracción de aquellas perspectivas en las cuales lo que hace el gobernó no tiene sustancia explicativa, sea la neoliberal en la que el Estado reduce su participación a un mínimo y brinda la seguridad jurídica para que actúen las fuerzas del mercado o marxista estructural, para la cual el Estado capitalista es el Estado de los capitalistas y su accionar anecdótico en un devenir histórico global (Aguilar Villanueva, 1994; Sunkel, 2007)-, son un espejo en el que se reflejan las transformaciones de la relación entre la sociedad y el Estado (Mendíaz 2007:1), una relación cambiante e histórica.

Las grandes obras de infraestructura contienen un dilatado proceso de desarrollo temporal tan sólo en su fase de implementación, lo que implica -al menos en el subcontinente- cambiantes configuraciones tanto de la sociedad como del Estado que les dieron origen al momento de su evaluación. De allí el interés historiográfico que adquiere, en nuestra opinión, tanto el proceso de definición política de la misma como la forma de resolución de un problema público, su diseño de intervención concreta, su implantación e incluso su evaluación.

Sin embargo, ha sido advertido por la perspectiva neoinstitucionalista que la mayor parte de las investigaciones de análisis de políticas públicas fueron a-históricas, o de un presente de trazo grueso, haciendo abstracción de las tradiciones legales e institucionales, de los acontecimientos que dieron forma al acuerdo político-administrativo, etc.; es decir, a la Historia (Meny y Thoenig, 1992: 236). El renovado interés por la Historia en el marco de las políticas públicas y por los estudios longitudinales contribuye a enriquecer y a hacer un poco más pluridisciplinar el campo. Como afirma Peter Knoepfel y sus colegas, "El policy making debe contemplarse como un proceso sumergido en un contexto social donde los actores y las estructuras emergen y cambian gradualmente hasta llegar a la situación presente." Y agrega "...el estado esencialmente a-histórico de la investigación actual requiere, seguramente, un mayor interés por la Historia." (Knoepfel et al., 1987:181). La propia idea de "ciclo" en las políticas públicas, aunque la figura más adecuada podría ser una espira ya que nunca se parte del mismo punto, ni ninguna política pública es totalmente nueva o eterna, es esencialmente histórico.

Proponemos entonces un análisis de las etapas del "ciclo" de las políticas públicas de una obra de infraestructura de magnitud, lo cual implica, tautológicamente, un análisis histórico, si bien de periodización compleja. Por un lado, todas las grandes obras de infraestructura comienzan a ser diagnosticadas años e incluso décadas antes de su inclusión en la agenda; y por otra, este tipo de obras tienen una vida útil que, con mantenimiento o no, suele llegar hasta el presente, con lo cual el fenómeno estudiado, de alguna manera, se sigue produciendo. Nuestra guía de análisis es, por un lado, las condiciones de producción de la infraestructura que es el resultado de un polígono de fuerzas, de una relación entre actores públicos y privados, dotados de recursos de diferente índole y magnitud, dentro de un marco institucional en este caso también cambiante. Por el otro, el producto de esa puja de actores que se produce en la arena de las políticas públicas, y que se expresa en las cuatro etapas clásicas que intentaremos colocar dentro de una periodización para esta obra.

Estudiar las políticas públicas sustantivas, en este caso de infraestructura física, se centra en el efecto que la construcción de las mismas puede tener sobre los índices de desempleo, reducción de la pobreza, el apoyo a las regiones periféricas o la forma de utilización de los recursos (financieros) públicos. El objeto del trabajo presenta, como 
señaló (Friedberg, 1993:22) dos facetas interdependientes: por una parte, producir un conocimiento concreto que deriva del contexto de la acción analizada y, por otra, ayudar a los implicados a situarse en relación a ese conocimiento, y por tanto a sacar consecuencias de todo ello, integrándolo en sus prácticas, y modificándolas si fuera necesario a partir de la experiencia histórica.

\section{La arena de resolución de las políticas públicas}

Un puente, una carretera, un túnel, tienen como sustancia preponderante cantidades diferentes de cemento, arena, piedra, acero y agua. Sin embargo, antes de llegar a esa sustancialidad estas obras están hechas de palabras, o más precisamente de argumentos. Estos argumentos -o un silencio proactivo- son vertidos por actores públicos y privados involucrados de alguna forma en la política que intenta resolver un problema definido, políticamente, como público. El alcance de estos argumentos impacta más o menos en el alcance de la resolución del problema (o en la no resolución) según los recursos de que dispongan los actores y la magnitud de los mismos. Finalmente, la resultante de las fuerzas desplegadas por los actores, es decir la política pública ejecutada en concreto, se inserta en un marco institucional que pone límites o potencia los recursos de los actores.

El modelo de análisis que aplicamos es de tipo causal (Subirats et al., 2008), lo que implica que en la definición del problema hay actores (personas físicas o jurídicas) que son interpretadas, directa o indirectamente, como la causa del problema o aquellos que impiden su resolución y cuya conducta es necesario modificar para resolverlo o atenuarlo (grupos-objetivo). Además, hay un segundo grupo integrado por actores (personas físicas o jurídicas) a los que el problema público afecta de pleno y cuya resolución los beneficiaría directamente (beneficiarios finales).

Por otro lado, sin estar directamente implicados en el problema hay dos grupos de actores que reciben los efectos colaterales de la implantación de la política pública, uno de forma negativa (afectados) y otra de forma positiva (favorecidos). En torno a estos cinco grupos de actores, y al incluirse el problema en la agenda pública, se establecen implícitamente o explícitamente quiénes son los causantes (directos o indirectos) del problema (hipótesis causal) y quiénes padecen sus efectos negativos. A partir de esta operación diagnóstica se desarrollan las hipótesis de intervención, es decir la forma en que el problema podría ser resuelto.

En las etapas del ciclo de las políticas públicas y con intención de influir en el desarrollo de cualquiera de ellas se producen coaliciones (Sabatier, 1988), a veces extrañas, entre actores diversos (grupos-objetivo y oposición política, beneficiarios y gobierno $\mathrm{u}$ organizaciones ambientalistas y afectados, por ejemplo) que pueden desarmarse una vez de alcanzados los objetivos de algunos de los componentes (cuando la oposición política llega al poder, cuando el gobierno demora la ejecución, cuando la política pública beneficia finalmente a una localidad o provincia, o los afectados obtienen alguna prerrogativa).

En el caso que nos ocupa, definimos operativamente el problema público con una cita de un trabajo presentado al Primer Congreso de Profesionales de la Ingeniería de Entre Ríos en 1956 que nos parece lo sintetiza en tiempos muy cercanos a su inclusión en la agenda:

El colosal abrazo de los ríos Paraná y Uruguay ahoga el desarrollo económico de la Mesopotamia Argentina, una de las zonas privilegiadas del país. Si descartamos 


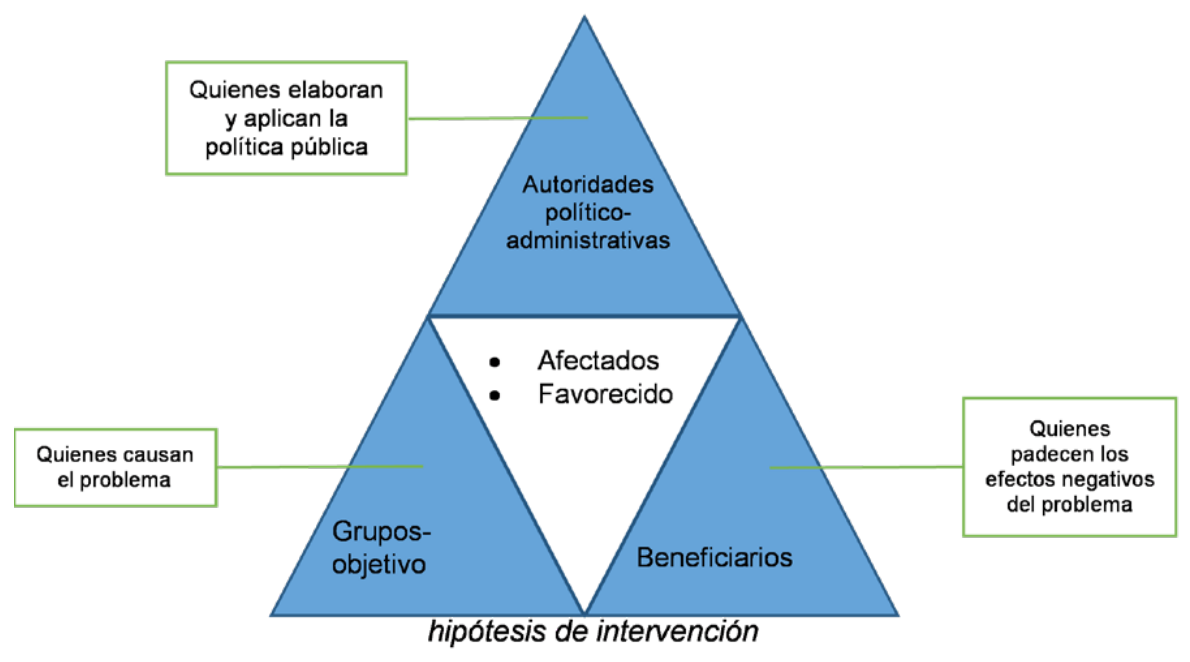

de toda consideración el problema de las comunicaciones permanentes con las repúblicas del Paraguay, Brasil y Uruguay, de indudable transcendencia internacional, y nos limitamos al panorama argentino, concluimos que el aislamiento de la Mesopotamia, al afectar profundamente la riqueza potencial encerrada en los ciento noventa y cinco mil kilómetros cuadrados de su superficie, repercute sensiblemente en la economía nacional y reclama urgentes y eficaces medidas para solucionar integralmente el problema (Álvarez, 1957:17).

El río Paraná oponía un formidable obstáculo a las comunicaciones terrestres donde “... los caminos y ferrocarriles que cruzan transversalmente el país al llegar a las orillas del Paraná desvían su trazado y continúan en forma paralela al cauce, como si carecieran de fuerzas para intentar la aventura del cruce." Los limitados métodos para efectuar ese cruce en ese entonces, evaluaba el ingeniero Álvarez, llevaban a que "contrastando, su velocidad con los vehículos modernos, el trayecto fluvial representa ocho o nueves veces el recorrido terrestre." Mejorar el estado de las carreteras y las redes ferroviarias y, sobre todo, la vinculación permanente con las provincias del Litoral eliminando el inconveniente de la travesía fluvial eran las medidas a tomar para permitir que un tránsito de cargas y pasajeros que alcanzaba "ponderable significación" multiplicara su apreciable acrecentamiento.

En cuanto a su intensidad, los actores políticos consideraban obviamente que era un problema serio, digno de tomarse en consideración, al grado de movilizar la opinión pública o generar una intervención inmediata de los poderes públicos. Su perímetro o audiencia se extendía geográficamente a toda la mesopotamia e incluso a los países limítrofes y socialmente, a todos los agentes económicos vinculados con la producción, el transporte y el comercio entre la Megapotamia y la argentina continental, Brasil, Uruguay e incluso Bolivia y Chile. Se trataba de un problema crónico, pero a pesar de ello no perdió, todo lo contrario, importancia y peso en la agenda gubernamental, cuya conclusión significaba un galardón para cualquier administración política. En cuanto a su urgencia, se trata de un problema de escalas. Las balsas unían a la mesopotamia con el continente, pero esto requería además de algunas obras de infraestructura para su continuidad y el pago del trasbordo por unidad de traslado, para un servicio lento y que cada vez provocaba mayores cuellos de botella en los puntos de embarque mientras se desarrollaba el transporte automotor, a pesar de las mejoras producidas en la primera mitad del siglo XX en el recorrido y logística de las balsas (Mateo, 2016). La decisión política condensó el proceso histórico del problema y definió el debate que se había suscitado entre actores políticos y técnicos.
Figura 2 Triángulo de actores en las políticas públicas. Fuente: elaborado a partir de Subirats et al. (2008). 
Los productores y comerciantes de Santa Fe y Entre Ríos serían los beneficiarios finales de esta conexión que favorecería por carácter transitivo a los transportistas que padecían el cuello de botella del cruce en balsas y a la población del Litoral en general y en particular de Santa Fe y Entre Ríos al verse reducidos los costos y tiempos del transporte. Colateralmente, los balseros y operadores del tráfico fluvial, y en alguna medida las corporaciones técnicas con posición dominante para afrontar este tipo de obras al ser desplazadas del proyecto elegido fueron los afectados.

Antes de ingresar en la agenda pública existían una media docena de proyectos que incluían puentes, balsas, túnel o métodos combinados para solucionar o atenuar el problema, es decir, no existían dificultades técnicas para afrontarlo. Sin embargo, se enfrentaban dos posiciones no necesariamente divergentes en la profundidad ideológica. Por un lado, los representantes de las fuerzas productivas de la región, expresadas en el argumento del ingeniero Álvarez y por otro la estrategia de defensa nacional expresada por las fuerzas armadas.

Las hipótesis de conflicto imaginadas por los comandos militares (en Brasil y en Argentina desde la finalización de la Guerra del Paraguay) sacrificaban de hecho a la región como tapón protector ante posibles tensiones fronterizas, limitando el progreso de los proyectos nacionales para la conexión material (Sánchez Gijon, 1990:107). A tales límites se refería institucional y retrospectivamente, por ejemplo, la Bolsa de Comercio de Córdoba:

Entre Ríos ha sido víctima del aislamiento junto a Corrientes y Misiones ya que, debido a las hipótesis de conflicto, eran la porción de territorio que podía perderse si Brasil nos invadía. Durante muchos años no existieron obras de infraestructura que la unieran con el resto del país. Con una concepción inspirada en la teoría de la seguridad nacional, desde el gobierno de Buenos Aires no se aprobaban los proyectos de puentes hacia Santa Fe y Buenos Aires. La mejor defensa contra los brasileros era el río Paraná, verdadera frontera de la Argentina para el gobierno central. La única actividad que se promovía era la instalación de regimientos para la defensa del territorio nacional. (Bolsa de Comercio de Córdoba, 2004)

El Río Paraná, obstáculo para la economía, tenía condiciones virtuosas para la defensa nacional. Las fuerzas armadas, desde un punto de vista politológico, sociológico e histórico son un actor un tanto particular. Una de las características que han tenido durante todos los regímenes autoritarios es que se han comportado como un actor político, esto es, como un actor con capacidad de acción estratégica y con capacidad de decidir su grado de intervención en la acción política. Cuando pensamos en regímenes democráticos la definición de las fuerzas armadas, o el lugar esperado de las fuerzas armadas, supone subordinación de los actores políticos civiles; es decir, que las fuerzas armadas no deben comportarse como actores políticos. Por lo tanto, se podría pensar que un objetivo general de un régimen político democrático respecto a las fuerzas armadas tiene que ver con la subordinación, que supone entre otras cosas una limitación de su autonomía para la gestión política. Esta subordinación al poder político ha sido bastante utópica por la característica de los recursos de que disponen las fuerzas armadas y las han convertido en un actor paraestatal por lo menos hasta finales del siglo pasado (hoy ese rol lo cumplen las fuerzas de seguridad interior, la policía, la prefectura y la gendarmería); sin embargo, no lo ha sido la subordinación al poder económico.

Por otro lado, como advierte Eduardo Basualdo, en la segunda etapa de la sustitución de importaciones, especialmente a partir de 1966, se dio forma a la primera versión de la denominada Doctrina de la Seguridad Nacional que como una de sus hipótesis centrales asumía que la superación de las contradicciones entre capital y trabajo requería, 
junto al ejercicio de la represión estatal, el asentamiento de un proceso de desarrollo económico que les planteara a los sectores subalternos ciertas vías para el ascenso social y el mejoramiento de sus condiciones de vida (Basualdo, 2006:118). Esto último sería revisado en la década siguiente a la luz de sus resultados. En el caso del túnel, y pese a las reticencias del poder central, no es un dato menor que un general en uso fáctico del poder ejecutivo (Pedro Eugenio Aramburu) puso la primera piedra fundamental (hubo dos) y otro general en igual ejercicio (Juan Carlos Onganía) lo inauguró.

Reiteramos, no toda acción del Estado es una política pública, pero no hay política pública que no tenga participación del Estado, y esta lo es mucho más en los regímenes autoritarios. Siguiendo a Lindblom, (1991:15), la elaboración de políticas públicas es más complicada en los sistemas democráticos, respecto de los regímenes no democráticos, simplemente por el mayor número de actores que intervienen en las democracias. A esto se suma el ingrediente de federalismo al menos formal del sistema político argentino. En el período en el cual se desarrollan los aspectos esenciales de la obra los niveles de legitimidad del Estado fueron cambiando desde una democracia restringida por la proscripción de uno de los principales partidos políticos en Argentina hasta una dictadura cívico-militar de un Estado "burocrático autoritario" (O’Donnell, 1982).

Dada la magnitud de estas obras y la carencia de medios técnicos propios para abordarlas directamente, el Estado, debió adjudicarlas por administración a empresas privadas, asumiendo en tal caso un rol regulador y financiador, en calidad de comitente. No obstante, cabe aquí una adenda respecto a qué Estado nos referimos. Ante la falta de apoyo manifiesto del gobierno nacional aun en períodos cuasi democráticos, haciendo uso por primera vez de una atribución constitucional, la obra fue contratada por dos Estados subnacionales. En efecto, los gobernadores de Santa Fe y Entre Ríos (del mismo signo político o cercano al de los gobiernos en los interregnos semi-democráticos) utilizaron, el artículo 107 de la Constitución vigente hacia 1960, que permitía acuerdos económicos de desarrollo entre provincias con el sólo requisito de informar al Parlamento y utilizar recursos propios. ${ }^{4}$

El triángulo de actores quedó conformado entonces por las diferentes expresiones del gobierno nacional y subnacional y sus corporaciones burocráticas (donde destacó el Banco Central) con discursos heterogéneos e incluso enfrentados -aun cuando las provincias estaban intervenidas en momentos dictatoriales-, como las autoridades político-administrativas (APA) de la política pública de la integración megapotámica.

Como población-objetivo tenemos a las fuerzas armadas, una corporación paraestatal con fuerte injerencia sobre el gobierno (solo en teoría subordinada al poder político durante las ventanas semi-democráticas). Como agente profesional este actor no concordaba con la obra por los motivos expuestos, pero como agente político su subordinación al poder económico y la concepción expresada de la Doctrina de Seguridad Nacional, llevó no sólo a aceptar la finalización de la conexión sino a impulsar un ambicioso plan de obras (Castellani, 2002:47), que descentralizó la construcción de la obra pública, dando lugar al surgimiento de lo que posteriormente se denominó la "patria contratista" integrada por un conjunto de grupos económicos locales cuyos "decanos" eran Pérez Companc y Techint (Basualdo y Barrera, 2015: 278). Estas empresas contratistas del Estado se vieron afectadas al menos en la construcción del túnel, dada la contratación internacional de la obra y el carácter del proyecto que excedía sus "capacidades tecnológicas" (Bell y Pavitt, 1995), no así en la opción puente. Estas empresas manifestaron su oposición al proyecto mediante sus representantes corporativos (Cámara Argentina de la Construcción, Centro de Ingenieros, etc.). A estos afectados se sumaron en sordina todos los operadores del tráfico fluvial en balsa (de control estatal nacional) ${ }^{5} \mathrm{y}$ las lanchas de pasajeros $\mathrm{y}$ transbordadores privados.
4. “Art. 107. Las provincias pueden celebrar tratados parciales para fines de administración de justicia, de intereses económicos y trabajos de utilidad común, con conocimiento del Congreso Federal; y promover su industria, la inmigración, la construcción de ferrocarriles y canales navegables, la colonización de tierras de propiedad provincial, la introducción y establecimiento de nuevas industrias, la importación de capitales extranjeros y la exploración de sus ríos, por leyes protectoras de estos fines, y con recursos propios."

5. Si bien el túnel subfluvial canalizó la mayor cantidad de vehículos, las balsas siguieron siendo utilizadas para transportar camiones con combustible y sustancias peligrosas, que no podían acceder al túnel, hasta la habilitación del puente Rosario-Victoria en 2003. Esto provocó una disminución paulatina de la demanda de las balsas, hasta suspenderse en noviembre de 2009 (El Litoral 26-11-2009). 


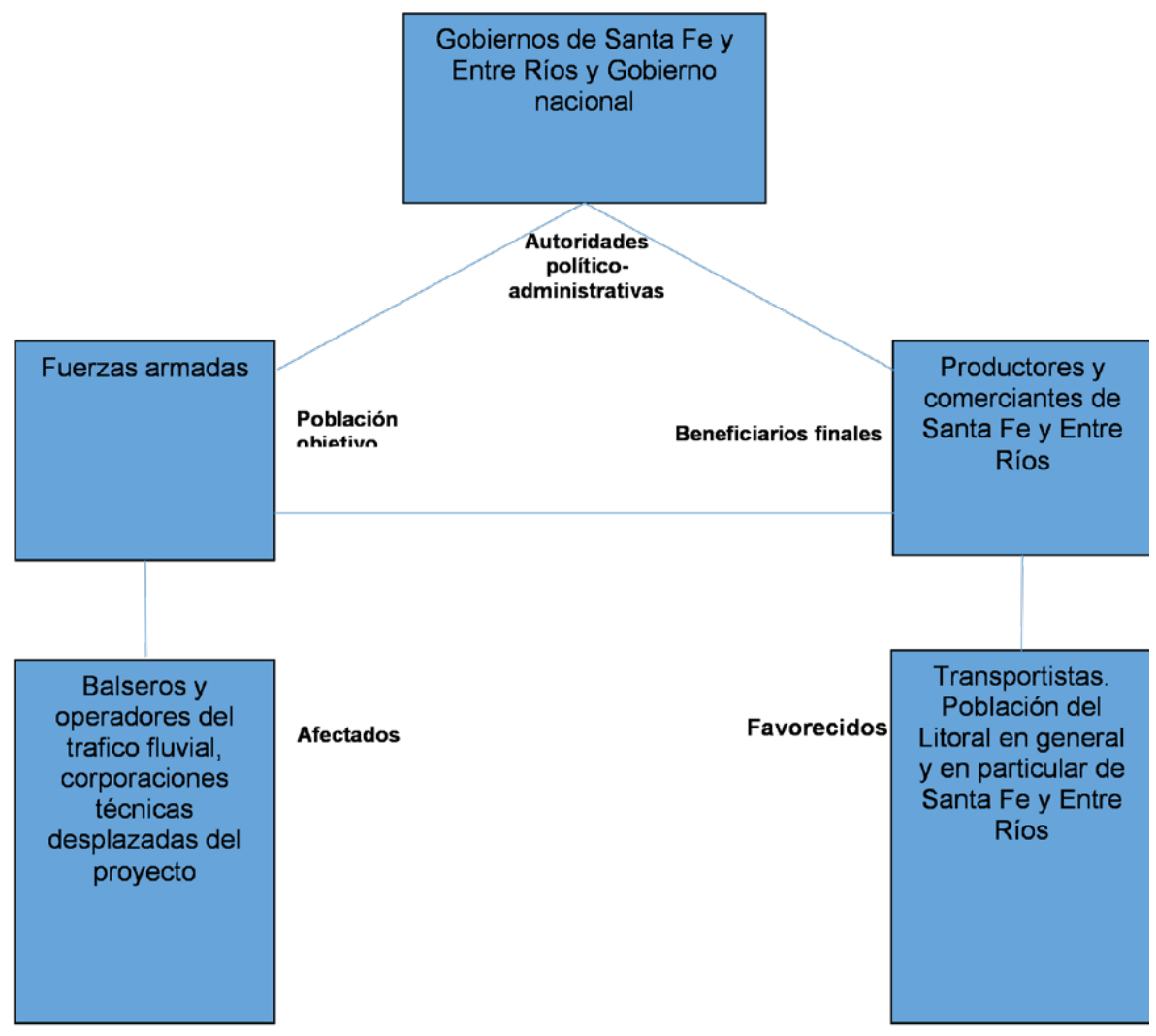

Los beneficiarios finales directos, reiteramos, fueron los productores y comerciantes de Santa Fe y Entre Ríos que además de la velocidad de circulación de mercancías, muchas de ellas perecederas tales como los de la producción avícola u hortícola (Reffino, 1969: 94), reducían notablemente los costos de circulación del capital en tránsito. A ellos se sumaron como favorecidos colaterales los transportistas de mercancías, que podían obtener una mayor rentabilidad por un mayor número de viajes y que su vehículo no fuese utilizado como depósito, además de la población en general de la región. A su vez, como afirma el estudio más profundo realizado sobre el túnel, el fin del aislamiento constituyó el inicio de la industria turística provincial (Retamar et al., 2016:39).

El marco institucional lo dio la Constitución Nacional vigente, o mejor dicho una zona de incertidumbre generada por ésta y el uso dado por la fracción subnacional de los actores político-administrativos al artículo 107. Este artículo, uno de los últimos de la Constitución ofreció un recurso legal en relación a otro económico, sin embargo, en la arena de la política pública los recursos puestos en juego por los actores fueron de distinta índole ya que la fortaleza de los argumentos no dependía sólo de sus intereses respectivos, sino también de los recursos que lograran movilizar para defender sus posiciones con relación con los objetivos, a los instrumentos y a los procesos de elaboración de la intervención pública. ${ }^{6}$

\section{Los actores y sus recursos}

La forma de intervención para tratar de resolver el problema surgió de un acuerdo entre las dos jurisdicciones provinciales. Estos actores públicos adjudicaban a otros actores públicos del sistema institucional (el gobierno nacional y las fuerzas armadas) las causas probables del problema. Desde el poder central -liderados por el dos veces Ministro de Economía en el período, el capitán-ingeniero Álvaro Alsogaray- insistían
Figura 3. Triángulo de actores del Túnel Subfluvial. Fuente: elaborado a partir de Subirats et al. (2008).

6. Los recursos pueden ser el marco legal, recursos humanos, económicos, medios de comunicación e información, niveles de organización, consenso social, infraestructura, apoyo político, capacidad de coacción o manejo de los tiempos. 
con el argumento en perfeccionar el método de balsas como medio de comunicación. Si bien el juego de actores y recursos podría dar lugar a una investigación en sí misma, vamos a reseñar los aspectos que a nuestra visión fueron más relevantes.

El marco legal fue un primer escenario para contraponer recursos. En principio, los gobernadores se acogieron por primera vez al mencionado artículo constitucional que los liberaba de la necesidad de contar con la venia del gobierno nacional. Pero ello no acabó allí. Dado que los cursos fluviales desde el lecho de los ríos hasta su espacio aéreo son de jurisdicción nacional, la opción túnel por debajo del fondo del río constituía la continuidad natural de las provincias rivereñas y, por lo tanto, al menos, una zona de incertidumbre para el marco legal aprovechada por los gobiernos subnacionales.

En cuanto a recursos humanos, en su aspecto cuantitativo las grandes obras de infraestructura son fuertes demandantes de fuerza de trabajo con diferentes niveles de especialización, lo que provoca movimientos de personas e incluso familias de dentro del país, inclusive de países limítrofes (por ejemplo, se han verificado trabajadores provenientes de Bolivia). Desde el punto de vista cualitativo, se midieron en el debate distintos tipos de estrategas: militares y técnicos, incluyendo dentro de esto últimos abogados e ingenieros.

Los recursos económicos jugaron, obviamente, un rol central. La constitución nacional en su artículo cuarto impedía el endeudamiento externo de los gobiernos subnacionales; ${ }^{7}$ y el artículo 67 confería esa atribución sólo al Congreso Nacional. Por lo tanto, los recursos económicos debían obtenerse de acervos propios, de fondos del tesoro nacional (por coparticipación federal, por endeudamiento del Estado o préstamos a las provincias) o de fuentes creativas. Todas ellas fueron utilizadas en alguna instancia cómo veremos en el desarrollo de la obra. El Estado nacional adelantó fondos coparticipables y realizó préstamos, la empresa que construyó la parte esencial de la obra (Hochtief AG, que aun la publicita como una de sus grandes obras) ${ }^{8}$ tenía como importante accionista al segundo banco de Alemania (el Commerzbank AG) ${ }^{9}$ y consiguió un aporte de éste a devolver en dos años (Reffino, 1969:97; Retamar et al., 2016). Hasta se aplicó un gravamen a las localidades de espectáculos deportivos y culturales para financiar la obra. Pero quizás el aspecto más notable es la utilización por primera vez en el país del recurso del peaje para financiar (o amortizar la financiación) de la obra. En efecto, al explotar otra zona de incertidumbre legal, los letrados provinciales argumentaron que, dado el carácter oneroso del tránsito por balsa, recordemos que estatal y nacional, el peaje era un equivalente al peaje para la circulación por una infraestructura pública ya que el valor del mismo se calcularía en función de las tarifas de las balsas. Por su parte, las fuerzas armadas contaban con limitar el acceso a los recursos económicos dada su posición dominante con respecto al poder central.

En cuanto al recurso información, tanto las autoridades como las fuerzas armadas contaban con la información general necesaria (tanto técnica como legal). Sin embargo, estas últimas poseían un plus que provenía de información clasificada que ellas mismas producían, por cuestiones de seguridad nacional. Al margen de esto las hipótesis de conflicto con Brasil eran harto conocidas por la propia exposición pública de los referentes militares.

En lo que respecta al recurso organización, dado el sistema federal del Estado argentino intervienen tres organigramas institucionales, el nacional y los dos subnacionales. Sin embargo, el convenio suscripto por las provincias creaba una organización ah hoc en la cual los Estados provinciales delegaban gran parte de las decisiones. En su artículo segundo expresaba su conformación:

Las Partes Signatarias acuerdan la constitución de una Comisión Interprovincial compuesta por cinco delegaciones ad-honorem designados respectivamente por
7. Art. 4. "El Gobierno federal provee los gastos de la Nación con los fondos del Tesoro nacional formado del producto de derechos de importación y exportación, del de la venta o locación de tierras de propiedad nacional, de la renta de Correos, de las demás contribuciones que equitativa y proporcionalmente a la población imponga el Congreso General y de los empréstitos y operaciones de crédito que decrete el mismo Congreso para urgencias de la Nación, o para empresas de utilidad nacional."

8. http://www.hochtief.com.

9. El Commerzbank AG era propietaria (o lo sería) del 11,53\% del paquete accionario de Hochtief AG al juzgar por lo que informa la página web de la última. 
cada Provincia. Cada representación estará integrada por tres técnicos -dos en ingeniería y uno en finanzas- un letrado y un miembro de las fuerzas activas.

Sendos ejecutivos se reservaban tanto el derecho de veto, de desempate en el caso que algunas decisiones no llegaran al consenso y en general la última palabra en cada paso. Por su parte, las atribuciones otorgadas a la comisión eran, amplias y consistían en:

»Dictar el Reglamento a que ajustará su actuación, que será sometido a la aprobación de los Poderes Ejecutivos.

»Confeccionar las bases y pliegos de condiciones para la licitación pública nacional e internacional del anteproyecto y presupuesto preliminar, proyecto definitivo y construcción del túnel subfluvial materia del presente tratado, y someterlos a los Poderes Ejecutivos.

» Llamar a licitación sobre las bases aprobadas por los Poderes Ejecutivos; verificar la recepción de las propuestas en acto público, realizar su estudio, y aconsejar a los Poderes Ejecutivos la adjudicación que considere, técnica y económicamente, más conveniente o, en su caso, el rechazo de todas.

»Supervisar la marcha de las obras, realizando a tal efecto las tareas de estudio, inspección, superintendencia, emisión de certificados, recepción provisoria y definitiva, y toda otra que le sea asignada en los pliegos de condiciones y respectivo contrato de obras públicas.

»Confeccionar y someter a las Provincias signatarias el presupuesto anual de gastos de la Comisión.

»Presentar las rendiciones de cuenta anualmente y cada vez que le fueren solicitadas.

» Proyectar el estatuto orgánico del Ente Autárquico Interprovincial del Túnel, al que se confiará el cuidado, vigilancia y administración de la obra una vez recibida definitivamente -lo que será materia de un nuevo tratado entre ambos Gobiernosdebiendo prever dicho estatuto la instalación de los organismos de dirección y administración, sus atribuciones, deberes y responsabilidades, recursos, domicilios del Ente, jurisdicción, sistemas de contralor administrativo y legal.

El último artículo refiere al organismo ex post a crear para la administración y control de la obra ya en funcionamiento, el cual se ocupa de la gestión del túnel en la actualidad.

Simultáneamente, las fuerzas armadas son en todo el mundo ejemplos de burocracias por excelencia. El hecho de que estas organizaciones manejen ciertos recursos especializados con respecto a sus autoridades políticas, inevitablemente, estructuralmente les otorga una fuerte capacidad de lobby. El estado subnacional por su parte, tuvo durante el proceso dificultades para ejercer su autonomía dado que, por un lado, no pudo desmantelar los "anillos burocráticos" (Cardoso y Faletto, 2002:211) existentes y mejorar sus capacidades institucionales y, por otro, porque varios de los cargos en el gabinete nacional fueron ocupados directamente por miembros de las grandes empresas que, obviamente, mantuvieron vínculos muy estrechos con los sectores capitalistas (Niosi, 1974:48).

El recurso "derecho" se remplaza en ocasiones por el recurso "consenso" (Subirats et al., 2008:91), Salvo la oposición puntual de la población-objetivo y las reticencias de algunos equipos económicos y directores del Banco Central la obra no tenía oposición; y prueba de ello es que no hubo quejas acerca del mencionado pago del gravamen especial por parte de los ciudadanos en las provincias contratantes. Por lo tanto, este recurso fue esgrimido fuertemente a favor de la consecución de la obra. Por otro lado, el sacrificio de la Megapotamia ante una posible (aunque no probable) invasión brasileña no era un argumento que generara consenso a favor de la población-objetivo, sobre todo luego del acercamiento económico entre ambos países luego de la crisis de 1930. 
En tanto al recurso "tiempo", aun cuando un problema sea definido políticamente como público y llegue a la agenda gubernamental (la despenalización del aborto es uno de los ejemplos más palpables) sufren procesos de incubación interna (popularmente conocido en Argentina como "cajoneo") o disipación al pasar su ventana de oportunidad. Para que esto no ocurriera los mandatarios provinciales tuvieron en el candelero permanentemente las gestiones relacionadas con la obra, amplificándolas a través de la prensa. Pero el factor tiempo en las grandes obras de infraestructura es utilizado también de forma especulativa una vez iniciada la obra. Como bien señala Ana Castellani, "la Ley 12910 o Ley de Mayores Costos, promulgada en 1947, permite que las empresas contratistas reclamen modificaciones en los precios de los contratos de obra aduciendo incrementos en los costos de producción por diversos motivos (aumento de los insumos, del costo de la mano de obra, de los fletes, etc.)" (Castellani, 2002:56). Es decir, hasta iniciada la obra el recurso tiempo puede jugar a favor de la poblaciónobjetivo, pero una vez iniciada (e invertidos recursos públicos) la prolongación de la misma por causas de financiamiento, por ejemplo, puede ser un recurso que le juegue en contra tanto a aquellos como a las autoridades político-administrativas. En el caso que nos ocupa fue un argumento de los Estados subnacionales para presionar sobre el Estado nacional.

El recurso infraestructura comprende al conjunto de bienes tangibles (una carretera, a un río o un bosque, edificios, etc.) de los que disponen los diferentes actores públicos o privados, ya sea porque tales bienes les pertenezcan, ya sea por que dispongan de su uso. En algunos casos, como en el que nos ocupa, la propia política implica es el acrecentamiento de este recurso. En este caso, algunas obras de acceso a las balsas, como el puente colgante entre Santa Fe y la isla Timbó y el que se construyera sobre el río Colastiné (Mateo, 2016) fueron incorporadas como recursos a favor de la obra. Por otro lado, el argumento dirigido hacia los afectados a favor de la intervención túnel sobre la alternativa puente -solución esgrimida por las corporaciones técnicas-, fue que el túnel al fundarse sobre tierra firme era prácticamente insensible a las cargas, es decir que admitía el material militar más pesado que se encontraba en uso y aún el que en el futuro se utilizara. El puente, en cambio, tenía un límite de carga que restringía el paso de material pesado del ejército. Además, dada la tecnología disponible, el puente podía restringir la navegación mientras que el túnel por debajo del lecho no producía cambios en este aspecto. El río, como infraestructura de órbita nacional fue de alguna manera soslayado como vimos por la construcción debajo de su lecho.

El apoyo político como recurso fue esgrimido casi monopólicamente por los Estados subnacionales. El aislamiento de la Megapotamia y los enfrentamientos históricos de dos provincias con un fuerte acerbo de federalismo fueron argumentos de mucho peso. Para sumar activos de apoyo las gobernaciones implicadas convocaron a un encuentro de gobernadores del Litoral en julio de 1959 en Paraná, en la que si bien no todos los detentadores del ejecutivo provincial asistieron si lo hicieron sus representantes y tuvieron la oportunidad de escuchar expresiones de un "federalismo practico" por parte los gobernadores cuyo nombre lleva actualmente el túnel subfluvial. En el debate parlamentario del informe de las provincias de la utilización de la prerrogativa constitucional, la voz opositora (El Litoral 1-7-1960) provino de un senador por el partido santafesino demócrata-progresista quién expresó, reconociendo el derecho de los gobernadores a hacerlo que "... nuestras preocupaciones nacen de que imprudentemente se lanzan los gobiernos a la iniciación de las tareas, comprometiendo las rentas públicas, sin beneficio práctico alguno." El débil argumento no obtuvo apoyo, y el Senado ratificó en las vísperas de la publicación señalada la presentación de los gobernadores que ya contaba con el aval de la Cámara de Diputados nacional.

A su vez, en agosto de 1958, a iniciativa de la Unión Industrial de Santa Fe, fue creada la Comisión Interprovincial Pro Túnel de Paraná a Santa Fe que estaba integrada por la 
Bolsa de Comercio, la Sociedad Rural, el Centro Comercial y la Asociación de Hoteles de Santa Fe y el Centro Comercial e Industrial, la Federación Económica, la Sociedad Rural y "dos instituciones a disponerse", suponemos para equilibrar en cinco por provincia (El Litoral, 24-8-1958). Estas instituciones apostaron a su vez tanto a la resolución del problema público como a la hipótesis de intervención que fuera finalmente adoptada.

Como sabemos, el monopolio legítimo del uso del recurso fuerza lo tiene el Estado. La característica de las organizaciones burocráticas es que, justamente por el tipo de recursos que tienden a controlar, su subordinación es limitada. En el caso particular de las fuerzas armadas eso está particularmente agravado por el hecho de que uno de los recursos que manejan diferencialmente es el control de los medios de fuego. Robert Kurtz ha insistido en destacar el rol de la revolución militarista en el desarrollo del capitalismo industrial e incluso financiero (Kurtz, 1997). Desde al menos el golpe de Estado de 1955, las fuerzas armadas asumieron el poder político cada vez más como representantes de los intereses de los grandes grupos económicos, llegando a su cenit en 1976. En este caso opinamos que fue el apoyo a la obra dado por el poder económico y la versión "desarrollista" de la doctrina de seguridad nacional que menciona Basualdo lo que limitó el argumento geopolítico del poder militar. La sociedad civil también puede oponerse a una política pública con acciones que van de una protesta en una plaza a una revolución social, pero nada ocurrió dentro de ese rango ni a favor ni en contra de la obra.

\section{Inclusión en la agenda y las hipótesis de intervención (1918-1956)}

Podemos identificar las primeras gestiones para unir materialmente a la Megapotamia con el continente por el año 1918 (Diario Santa Fe, 5-9-1918), con un puente ferro-automotor-peatonal (el proyecto incluía el arreo de ganado) a la altura de Ibicuy, uniendo a Entre Ríos con la provincia de Buenos Aires. Esto no implica que no hubiera manifestaciones o proyectos anteriores. Carlos Reffino cita, por ejemplo, un proyecto de 1911, también de un puente (Reffino, 1969:95).

Pero los proyectos quedaron en eso por décadas, hasta que el gobierno nacional comenzó a mover piezas al respecto hacia 1948. A finales de enero de ese año, El Litoral de Santa Fe (31-1-1948) publicaba la llegada de una comisión de Vialidad Nacional, encomendada del inicio de los estudios para la construcción de un puente (ferroviario y carretero) entre las ciudades de Santa Fe y Paraná. Pero tampoco se avanzó más allá de un proyecto que quedó incubado tras el golpe de Estado de 1955.

El volumen creciente del transporte fue generando cuellos de botella que hicieron cada vez más lento el traslado. Los cambios en la demanda generaron, como es habitual, el impulso de las tecnologías para acelerar los procesos de circulación, cuyo primer paso lo constituyó el tramo de la actual Ruta Nacional №168, paralela al río Tiradero Viejo y sobre la Isla Constanza en 1955 (Álvarez, 1955:84) que agilizó el traslado entre las balsas que cruzaban los ríos Colastiné y Paraná. Alivio, pero no solución definitiva del problema, ingenieros y políticos pusieron en marcha un proceso para incluir en la agenda pública una conexión material entre el continente y la Megapotamia. Si bien los proyectos de ley sufrieron procesos de incubación interna y disipación.

En el debate de diferentes proyectos a efectos de suscitar el ingreso formal de una vinculación física en la agenda pública jugó un papel relevante la opción entre puente o túnel.

\section{Las hipótesis de intervención \\ Los proyectos de los políticos}

Tempranamente, el proyecto "puente" tuvo como contraparte la opción de un "túnel subfluvial." En 1936 el legislador entrerriano, Atanasio Eguiguren, ya planteaba (aunque 
sin mucho sustento técnico) ambas alternativas para un trazado a la altura de Santa Fe-Paraná. Los túneles subfluviales, si bien eran ya una realidad efectiva en el mundo, tenían hasta ese momento pocos antecedentes. En el año 1899 se construyó en Berlín el primero bajo el Río Spree (el Stralau-Treptow), de una longitud de 454 metros, opción adoptada dado que este río comunica con el Mar Báltico por medio de canales y era necesario preservar la navegación. En 1927, en los Estados Unidos se inauguró el "Holland", bajo el río Hudson entre New York y New Jersey, de 2,5 km. En 1934, en Inglaterra fue construido un túnel de 3.180 metros, que une Liverpool con Birkenhadd bajo el Río Ramsey. Si bien se siguieron contrayendo túneles, como los "Lincoln I y II" en New York y los dos de la ciudad de La Habana -construidos por la misma empresa francesa que hizo el puerto de Quequén en Argentina-, eran estas tres obras los antecedentes que prologaban la idea para la vinculación de la Megapotamia en 1936.

Dos años más tarde, el diputado nacional santafesino Pío Pandolfo - primera iniciativa política santafecina al respecto- presentó al Congreso un proyecto de ley para estudiar una comunicación carretera y ferroviaria entre las ciudades de Santa Fe y Paraná. El trazado propuesto, arrancaba en un puente colgante sobre la laguna Setúbal, siguiendo hacia el Este hasta las proximidades del puerto de balsas de Colastiné, cruzaba el río con un puente, continuaba por las islas Timbó y Santa Cándida, llegando al río Paraná. En dicho lugar debía construirse otro puente de $1.500 \mathrm{~m}$ de luz, parte del proyecto que coincidiría con la propuesta del ingeniero Micheletti de 1937, del que hablaremos más adelante.

Siguiendo los lineamientos de la iniciativa de Eguiguren, el gobierno de la provincia de Entre Ríos encaró en el año 1945 el estudio de la vinculación carretero-ferroviaria de la Megapotamia, adoptando un trazado similar a los dos proyectos anteriores. Un puente colgante sobre la laguna Setúbal, siguiendo por la ruta nacional № 168, río Colastiné, islas Timbó y Santa Cándida y cruce del río Paraná. Este era el proyecto principal, aunque presentaba alternativas de menor costo que incluían balsas.

Como anticipamos, Vialidad Nacional en el año 1948 generó una comisión que estudió el trazado de un puente ferroviario-carretero entre el atracadero de balsas en el río Colastiné en Santa Fe y Bajada Grande en Paraná, vinculándolo con la ruta nacional № 168 y la ciudad de Paraná, mediante sendas obras de acceso. El puente tendría un largo aproximado de $6.000 \mathrm{~m}$ con dos secciones principales en los cauces de los ríos Colastiné y Paraná y un viaducto sobre las islas. Se completó el estudio del trazado incluyendo un nuevo puente sobre la laguna Setúbal y las perforaciones para la investigación del subsuelo entre Colastiné y Bajada Grande. Posteriormente el estudio fue suspendido durante el gobierno provisional de la llamada "Revolución Libertadora" sin alcanzarse a delinear la solución definitiva y su costo probable. (Álvarez, 1957:20).

\section{Los proyectos de los ingenieros}

En 1939, al año siguiente de presentado el proyecto Eguiguren, un ingeniero, Luciano Micheletti, presentó un proyecto concreto con dos opciones. Una de ellas consistía en dos puentes, uno de 400 metros de luz que cruzaría el Río Colastiné y otro de 1.500 de luz que cruzaría el Paraná. Iba configurándose el proyecto final, al menos en su trazado. En 1952, el mismo ingeniero, contemplaba también la posibilidad de un túnel entre Santa Fe y Bajada Grande, aunque no era su primera opción.

Mediante el Decreto 5149/54 del Ministerio de Obras Públicas se encomendó a un grupo de técnicos el estudio y la redacción del anteproyecto y presupuesto de un túnel subfluvial a través del río Paraná que uniría Paraná con Santa Fe. El II Plan Quinquenal elaborado por el gobierno nacional preveía la realización de obras de gran importancia y que contribuyeran a las aspiraciones de la Megapotamia para obtener un medio que 
le permitiera la intercomunicación con el resto del país. Es así que se les encomienda a los ingenieros Carlos Laucher, Ernesto Altgelt y Corrado Vittori, el estudio y redacción del anteproyecto y el presupuesto para un túnel bajo el río Paraná, entre las ciudades de Paraná y Santa Fe.

En 1955, el estudio publicó un informe que contemplaba dos posibles soluciones para el cruce del río Colastiné mediante puente y del Paraná mediante un túnel sub-fluvial. La primera y principal cerca de la desembocadura del arroyo Las Viejas, aguas arriba de la ciudad de Paraná y donde el ancho del cauce es de unos $1.600 \mathrm{~m}$. La segunda alternativa, se ubicaba cerca de Bajada Grande donde el espejo de agua es de unos $2.000 \mathrm{~m}$ de ancho. En ambos casos túnel y puente se unían por la RN №168. El costo total estimado -incluyendo el puente sobre el río Colastiné- era de 350 millones de pesos ( $1,148.115$ de U\$d de la época), y sería amortizado -capital, intereses y costos de transacción- mediante un peaje que era inferior a las tarifas del momento de las balsas, concesionándolo la explotación durante unos 40 a 50 años.

Una comisión del Ministerio de Obras Públicas de la Nación, haciendo algunas observaciones de orden técnico, calculó el costo de la obra principal en unos 600 millones de pesos (nos 2.000.000 de U\$d de la época). El informe estimaba que no era oportuno que el Estado Nacional ni las provincias interesadas afronten íntegramente con sus recursos la ejecución de la obra, dada la situación económica del momento, proponiendo o un sistema de financiación mixto o un derecho de peaje para la amortización de las inversiones y gastos de explotación.

Finalmente, en 1957, el ingeniero Marcelo Álvarez, (1957), proponía al eje Santa Fe-Colastiné-Paraná como el que ofrecía las mayores perspectivas para concretar la vinculación permanente con la Megapotamia, una solución mixta -puente sobre el Colastiné y un más efectivo sistema de balsas para el cruce del Paraná- destacando la necesidad inmediata de una vinculación carretera que incluya todas las opciones $y$, para una segunda instancia la ferroviaria debido a la diferencia de trochas entre los ferrocarriles mesopotámicos y el resto de la red adyacente (v.g. Schulte, 1959). Los años 1950 finalizaban sin acuerdo tras tres décadas de debate.

A mediados de 1960 los diputados Horacio Dominguera, Jorge Ferreira y Héctor Suaret (por Entre Ríos) e Isaac Breyter (por Capital Federal) presentaron al Congreso Nacional un proyecto de puente a la altura de Zárate en la provincia de Buenos Aires "destinado a unir los centros de producción mesopotámicos con los mercados de concentración y consumo de la Capital y zona de influencia" y "de romper el aislamiento a que está sometida desde antaño, por la carencia de cruces sobre el río Paraná" (AAC 1960:25). La alternativa de vinculación con Buenos Aires probablemente movilizó a las fuerzas vivas de Paraná y Santa Fe a insistir en el túnel.

\section{¿Túnel y no puente?}

La respuesta a esta pregunta tiene aristas técnicas y políticas. Desde el punto de vista técnico, los expertos afirmaban que, a diferencia de un puente, un túnel no padecía fatiga en sus materiales, de modo que sólo una catástrofe podría sacarlo de servicio. También que su vida útil era prácticamente ilimitada y permitía el cruce de material rodante (tanto civil como militar) sin limitar su peso ya que era prácticamente insensible a las cargas.

El puente en cambio, tenía un límite de carga que restringía el paso de material pesado del ejército. El puente, con pilares principales en el cauce, afectaba la libre navegación, mientras un túnel bajo el lecho del río no presenta ningún obstáculo a la navegación. El subsuelo en el río Paraná es óptimo para fundar el túnel, no así un puente de 
grandes luces y gran altura. Desde el punto de vista económico, el servicio anual correspondiente al túnel era estimado inferior al del puente. Finalmente, el túnel prácticamente no presentaba problemas de divisas para acceder a los materiales y a la tecnología -existía una fábrica de cemento portland en Paraná, en 1960 había comenzado a funcionar la planta de SOMISA para la provisión de acero y el resto de los materiales y mano de obra eran accesibles en la zona- ${ }^{10}$ en comparación con un puente metálico y de gran luz.

Desde el punto de vista político, Entre Ríos y Santa Fe, insistieron durante más de 50 años ante el Gobierno Nacional para que el mismo interviniera en la concreción de una obra que terminara con el aislamiento de la Megapotamia. Las gestiones languidecieron, en virtud de la jurisdicción en todo lo que se construye sobre los ríos navegables. Este limitante dio lugar a robustecer la idea del túnel en razón de que lo que se construye bajo el lecho del rio es de dominio provincial como prolongación de sus subsuelos (AAC, 1970:28-31).

El proyecto túnel tuvo sin embargo sus voces opositoras. Ya mencionamos las de la Dirección Nacional de Vialidad, a las que se sumaron la del Ministro de Economía, el Ingeniero Álvaro Alsogaray. El argumento central era el costo de la obra y lo inoportuno de la obra debido a la coyuntura económica que hacía más conveniente insistir en el sistema de balsas. Desde las esferas gubernamentales se respondía a estos argumentos con contrargumentos fogosos que incluían conceptos tales como la "falta de patriotismo"; la "tutela porteña" y un interés mayor por la ejecución de la "autopista Buenos Aires-La Plata." (El Litoral, 21-01-1960)

Finalmente, y citando publicaciones internacionales de grandes obras de ingeniería, se expresó la Asociación de Ingenieros de Santa Fe. En principio, como argumento bastante pueril que probaba que el puente era más conveniente, ofrecían la constatación estadística de que existían muy pocos túneles e infinidad de puentes. Argumentaban también el costo de expropiación de los accesos (algo que sin embargo afectaría también al puente). La tesis más fuerte, que presentaban citando un presupuesto presentado por la empresa alemana Gutehoffnungshütte, era que un puente metálico (v.g. importado) arrojaría un ahorro del $50 \%$ sobre el presupuesto oficial (Asociación de Ingenieros de Santa Fe, 1961). Estos argumentos, hechos públicos a las vísperas de la firma de los contratos de adjudicación, no hicieron mella en ellos y el proyecto túnel siguió adelante. A pesar de ello, el complejo puente sobre el río Colastiné y túnel subfluvial se instaló como proyecto y la financiación provincial lo ponía en marcha.

En 1960 los gobernadores de Santa Fe y Entre Ríos cuyos nombres lleva en la actualidad el túnel produjeron la definición política del problema público (DPP). Estos actores públicos adjudicaban a otros actores públicos del sistema institucional (el gobierno nacional y las fuerzas armadas) las causas probables del problema, quienes insistían en perfeccionar el método de balsas como medio de comunicación.

\section{El diseño de la obra}

En el mes de diciembre de 1959 los gobernadores de las provincias de Santa Fe y Entre Ríos acordaron la construcción de un túnel subfluvial, firmando ambas provincias el 25 de junio del año siguiente un tratado interprovincial que en su artículo primero establecía "la construcción de un túnel carretero subfluvial" y en el mismo artículo que "los gastos que demanden el cumplimiento del presente tratado y consecuente construcción del túnel serán atendidos por iguales partes por las dos Provincias" (Begnis y Uranga, 1960:2).

Con ello se provincializaba su realización, evitando las interferencias de las posiciones del Ejército y la injerencia directa del Ministerio de Obras y Servicios Públicos de la Nación,
10. El elemento tecnológico más oneroso, aunque reutilizable, importado, fue una grúa puente para la ubicación de los tramos de tubos de hormigón armado. 
de manera que fuesen las provincias las que decidieran lo más conveniente. La fortaleza jurídica estaba en la tesis de que por debajo del cauce cesaba la jurisdicción federal.

El acuerdo no surgió sin embargo totalmente de la osadía de los gobernadores. En 1956 la intervención militar de la provincia había solicitado al gobierno provisional la imperiosa necesidad de la obra siguiendo el proyecto de los ingenieros Carlos Laucher, Ernesto Altgelt y Corrado Vittori. La obra se declaró de interés nacional (decreto 7122/56) y hasta el presidente de facto Pedro Eugenio Aramburu puso su piedra fundamental el 1 de mayo de ese año. En setiembre de 1958 se llevó a cabo una licitación fallida en la que participaron la empresa Sttugart de Alemania y SAILAV S.A. de los autores del proyecto y apoyada por Comisión Interprovincial Pro-Túnel Paraná-Santa $\mathrm{Fe}$, fundada por representantes de entidades empresarias.

El acuerdo interprovincial creaba una comisión interprovincial de diez miembros, cinco por provincia, integrada cada una por tres técnicos -dos en ingeniería y uno en finanzas- un letrado y un miembro de las "fuerzas activas" (la citada comisión pro-túnel). Sujeta al veto de las gobernaciones la comisión ad honorem tuvo entre sus funciones la confección de las bases y pliegos de condiciones para la licitación, el anteproyecto y presupuesto preliminar, el proyecto definitivo, llamar a licitación, aconsejar sobre la mejor oferta (o rechazarlas todas), la supervisión de las obras y la generación de los organismos de gobierno del túnel.

La Comisión interprovincial, presidida por el subsecretario de obras públicas de Santa Fe, ingeniero Osvaldo Santi llevó adelante su cometido en el complejo proceso de licitación de obras (De Carli, 1960). El 31 de enero de 1961 en la Casa de Gobierno de Santa $\mathrm{Fe}$, tuvo lugar la apertura de las propuestas para la construcción del Túnel. Sólo hubo un oferente que estaba formado por un consorcio de empresas: la mencionada SAILAV S.A. (Buenos Aires, Argentina), responsable del proyecto, Vianini S.P.A. (Roma, Italia) ${ }^{11}$ que se ocuparía de la construcción de los tubos de hormigón armado y del dragado del lecho del río y Hochtief A.G. (Essen, Alemania) ${ }^{12}$ que realizaría el resto de la obra civil.

Estas empresas se comprometían a efectuar la totalidad de los trabajos de acuerdo con lo especificado en la documentación respectiva y de conformidad con el anteproyecto. Estas empresas cotizaron un precio total, por el anteproyecto y presupuesto preliminar: proyecto y presupuesto definitivo, y construcción definitiva del túnel, de \$1.992 240.000 nacionales (unos 6.500.000 de U\$d de la época), especificando además, que la confección del proyecto definitivo y presupuesto reconocerá un honorario del 2,9 por ciento del presupuesto final más el uno por ciento del mismo en que se aprecien los, gastos especiales, lo que representaba una inversión de 73 millones de pesos ( $E l$ Litoral, 31-01-1961), casi un millón de dólares de la época adicionales.

El proyecto inicial de la obra sufrió algunas pocas alteraciones, y fue basado en un sistema mediante el cual fuera realizado el Maastunnel de Rotterdam de 1373 metros, inaugurado en 1942 (El Litoral, 03-01-1961). Consistió en tubos de hormigón armado en 36 tramos prefabricados encastrables de 65,45 metros de longitud, 9.80 metros de diámetro inferior, 0,50 metros de espesor y un peso de 4.550 tn cada uno. ${ }^{13}$ Para ubicarlos se dragó el lecho del río bajo el cual se instalaron los tubos, se ejecutaron los apoyos a los niveles respectivos y posteriormente se sumergieron. Los tubos fueron fijados y estabilizados con hormigón de fundación rellenando la zanja dragada. Una vez que se presentaban y fijaban los tubos en su ubicación, se desagotaban y una vez conformado todo el trayecto comenzaron las obras de su interior. La calzada llevó una carpeta de rodamiento de concreto asfáltico de un ancho de 7,50 m, mientras que la altura hasta el cielorraso fue de $4,41 \mathrm{~m}$. Una pasarela provista de baranda metálica, permitía el desplazamiento del personal hacia los dispositivos de control, señalización y seguridad.
11. Empresa fundada en 1908 especializados en la en la construcción de estructuras (tuberías, muelles y productos hidráulicos) en hormigón.

12. Empresa fundada en 1874 con antecedentes importantes en grandes obras como el bunker de Adolf Hitler y que realizaría el traslado del templo de Abu Simbel en Egipto tras la construcción de la represa de Asuán.

13. Un tubo de empalme de 9,50 $\mathrm{m}$ construido en el lugar de su emplazamiento completaba el acople del tubo 36 con el edificio de ventilación del lado Paraná. 
Una innovación con respecto al proyecto inicial fue que, si bien el túnel fue concebido originariamente para que sirviera en forma exclusiva para el tránsito carretero, con posterioridad se previó que pudiera soportar también el ferroviario mediante la prevención de dejar anclajes perdidos en el pavimento para permitir la ulterior fijación de vías férreas de trocha media $(1,435 \mathrm{~m})$ correspondiente al mesopotámico Ferrocarril Urquiza.

Además de obras de arte como el azulejado de sus paredes laterales y la utilización de pinturas anti grasosas, la obra contó con una serie de notas técnicas de interés para la época, como el efecto de ventilación a fin de reducir el porcentaje de monóxido de carbono, el que lograba la renovación total del aire en menos de cuatro minutos mediante cuatro ventiladores emplazados en cada cabecera los cuales podían regularse en función del tránsito.

El sistema de iluminación era regulado por células fotoeléctricas y para regular el tránsito se instalaron semáforos cada cien metros y una red de altoparlantes para las indicaciones a los automovilistas. El control de la circulación interna de vehículos se logró mediante un circuito cerrado de televisión, con trece monitores en los tableros de la sala de comando ubicada en un edificio en el lado Paraná. En sus dos bocas un emparrillado de vigas de hormigón armado regulaba el acostumbramiento visual entre el exterior y el interior del túnel.

A todo lo largo del túnel se instaló una cañería de agua a presión contra incendios, con grifos de salida y sus correspondientes mangueras cada 100 metros, además de matafuegos. La energía eléctrica era suministrada por la usina de la ciudad de Paraná, pero en previsión de cortes se instalaron grupos electrógenos de arranque automático. Es decir, se utilizó la cresta de la ola de la tecnología en infraestructura existente al momento de su ejecución (Müller et al., 2013).

\title{
Ejecución y financiación
}

Las obras comenzaron en una fecha plena de simbolismo, el 3 de febrero de 1962 con la presencia del presidente de la Nación, Arturo Frondizi, pocos días antes de ser derrocado por un "pronunciamiento" militar. Frondizi había nacido en la ciudad correntina de Paso de los Libres en el corazón de la Megapotamia. El procedimiento financiero adoptado en principio fue que:

\begin{abstract}
la empresa recibirá como única contraprestación de parte de Estado, la concesión de explotación del túnel por un lapso de treinta años comprometiéndose el consorcio a depositar en un banco argentino la suma de dos millones de dólares, yéste abrirá una cuenta en pesos moneda nacional, a orden de la empresa, con la cual se atenderá el pago de los certificados de obra. La empresa cancelará posteriormente ese crédito con el producto de la explotación del túnel. (El Litoral, 30-06-1959).
\end{abstract}

Es decir, las empresas se harían cargo del costo financiero de las obras obteniendo recursos externos que amortizarían por medio de la explotación de la misma mediante el derecho de peaje. Este era una novedad en el país, cuyo antecedente se buscó y justificó en la aplicación de tarifas por parte de las balsas de pasajeros, que como de se dijo no eran otra cosa que una especie de prolongación de los caminos y que el Estado, al explotar este servicio público en forma directa, cobraba a pasajeros, carga, automóviles, camiones, etc. Esta facultad, a la que el gobierno nacional se oponía por entonces, fue posible bajo el agua por tratarse de territorio íntegramente provincial.

Este procedimiento animó al acuerdo interprovincial y a que las obras fueran afrontadas con recursos propios de las provincias (su jurisdicción sobre el túnel). Otro elemento 
a considerar que la mayor parte de la obra se pagaría en moneda nacional por cuanto prácticamente todos los materiales a utilizar serían argentinos. En divisas sólo se pagarían los equipos que no existieran en el país, como la grúa mencionada.

Acaecido el golpe de Estado del 20 de marzo de 1962, un mes más tarde, truncó el mandato de los gobernadores elegidos democráticamente, lo que provocó que los trabajos del Túnel Subfluvial sufrieran múltiples dificultades. Progresivamente, las obras volvieron a manos de la Nación por vía de la asistencia financiera a las provincias y un notable retraso respecto del cronograma original.

Los trabajos fueron realizándose con regularidad a lo largo del año, pero al finalizar éste el atraso en los pagos y la negativa del gobierno nacional de hacer aportes debido a la "crisis económica" (que la prensa adjudicaba a actitudes de "mal perdedor" por haberse afrontado la obra contra su negativa, reavivando todavía la opción puente) no sólo auguraban la paralización de los trabajos sino el pago de multas a la empresa y una onerosa recisión de los contratos. Comenzó entonces a estimarse la idea de un empréstito internacional para lo cual las provincias necesitaban del aval del Estado nacional, que requerían los inversores de Suiza, Alemania, Estados Unidos, Italia y el Reino Unido que fueron consultados. Para ello, las provincias proponían la emisión de bonos por 2.000 millones de pesos, mil para cada provincia y "responder de este modo a ese centralismo egoísta que pone piedras en el camino al desarrollo y progreso del interior del país, como si éste empezara y terminara en los lindes de la avenida de circunvalación que bordea a la capital federal." Mientras continuaban llegando materiales y las obras, que empleaban a más de dos mil operarios, no se detenían, pero se languidecían.

Hacia mediados de 1963 las obras se encontraban prácticamente paralizadas cuando un grupo de banqueros alemanes visitaron la obra ofreciendo financiación salvado el obstáculo del aval nacional. El agosto el presidente interino José María Guido visitó las obras sin hacer declaraciones. En setiembre se anunciaba un empréstito del BID a quince años por $12.500 .000 \mathrm{u} \$ \mathrm{~d}$ (el 50\% de lo estimado necesario para su finalización) a la espera de la homologación por parte de las nuevas autoridades constitucionales que no se concretó.

Los nuevos gobernadores, Aldo Tessio por Santa Fe (Unión Cívica Radical del Pueblo) y Carlos Contín (Unión Cívica Radical) por Entre Ríos propulsaron un proyecto de ley al Congreso Nacional, ya en enero de 1964, para declarar de prioridad nacional la obra del túnel, comprometiendo el apoyo de sus bloques. Días más tarde los gobernadores acusaban a las oficinas técnicas nacionales demorar en pronunciarse por "instinto centralista”. El informe, finalmente, recomendó insistir con el sistema de balsas.

La oposición de la Nación fue argumentada en la utilización de fondos propios en las mismas condiciones del otorgado por los bancos alemanes y el BID, que consistían en un préstamo en pesos $\mathrm{m} / \mathrm{n}$ a 25 años a pagar con una tasa del $10 \%$ anual, cuyas cuotas serían deducibles de la coparticipación nacional de impuestos. Esto implicó que ambas provincias decretaran sendos gravámenes para afrontar el pago de las cuotas de unos 200 millones al año entre ambas. La suma final otorgada fue de 2.647.500.000 pesos $\mathrm{m} / \mathrm{n}$, correspondiendo 1.325.700.00 pesos $^{\mathrm{m}} / \mathrm{n}$ a la provincia de Santa Fe y 1.321.800.000 pesos $\mathrm{m} / \mathrm{n}$ a la de Entre Ríos.

La dictadura tecnocrática autodenominada "Revolución argentina" (1966-1973) sin embargo asumió una actitud positiva a las obras. El decreto 17.257 de mayo de 1967 decía expresamente "...que la Nación no se había hecho presente con el esfuerzo que le correspondía para concretar una tan importante vinculación provincial y nacional. De tal manera -dice más adelante-, el gobierno de la Revolución Argentina adhiere ahora 
al esfuerzo ya realizado por entrerrianos y santafesinos contribuyendo a partir de la fecha a soportar junto con ambas provincias el costo de la obra hasta su finalización." El decreto tenía dos elementos más de singular importancia para las provincias. El primero de ellos, que los aportes facilitados anteriormente por la Nación a reintegrarse en valor dólar, lo serán "sin ninguna clase de reajustes" y "a los montos numéricos recibidos en pesos moneda nacional", es decir no serían afectados por la devaluación con la que había iniciado el gobierno revolucionario. El segundo, que "serán nombrados dos delegados de la Secretaria de Estado de Obras Públicas, que integrarán la Comisión interprovincial", con la al menos dudosa aclaración de que "sin que dicha participación implique limitar o disminuir las plenas atribuciones de las provincias" (El Litoral, 02-05-1967).

El 13 de diciembre de 1969, a 2.870 días de iniciadas las obras, la Megapotamia y el resto de la Argentina estaban unidas por primera vez por una carretera. La obra había costado 21.600.000.000 \$ 1 (61.320.085 U\$d de la época), un 39\% aportado por el gobierno nacional y el resto producto de aportes de las provincias rivereñas (37\% de rentas provinciales, $12 \%$ de recursos coparticipables e igual porcentaje del mencionado crédito del Commerzbank alemán vinculado empresarialmente a la firma Hochtief, afrontado por las provincias).

A casi cinco décadas el túnel subfluvial ha operado en forma ininterrumpida "con excepción de 24 horas en julio de 1983" (Kuchen 2005:3) y lo han traspasado más de 100 millones de vehículos a razón de 8.500 diarios y ha incrementado la simbiosis entre las ciudades de Santa Fe y Paraná. Los incrementos en la circulación y las desventajas que pose ante las cualidades actuales del transporte (la altura de 4,20 metros, las velocidades mínimas y máximas para el cruce, la prohibición de la circulación para vehículos con cargas peligrosas y para transeúntes, ciclomotores y bicicletas y la necesidad de corte de tránsito para los vehículos excedidos de ancho) han puesto en agenda la construcción de un nuevo puente que inicia un nuevo ciclo.

\section{Algunas conclusiones}

Un problema centenario de desconexión material entre la Megapotamia y el resto del país se resolvió en el último tercio del siglo XX con la conjunción de tres resoluciones políticas novedosas: la utilización del artículo constitucional que autorizaba acuerdos interprovinciales con motivos económicos, la opción túnel frente a la de puente y el sistema de peaje como forma de amortización del costo de la obra.

La unión material de la Megapotamia con el resto del país fue una iniciativa que suscitó un fuerte consenso general desde siempre. A pesar de ello debió superar algunas oposiciones por cuestiones geopolíticas, hasta que el aislamiento a medida que la circulación de mercancías se hacía más fluido por diversas razones (incremento demográfico, del consumo interno, incremento de vehículos, integración regional, etc.) vencieron esas barreras. Sin embargo, tal superación fue abordada por un acuerdo interprovincial que de alguna manera desafiaba al poder central y esgrimía argumentos propios del período de organización nacional referentes a la práctica del federalismo económico y político.

La opción túnel, a nuestro entender, fue una opción más política que técnica. Implicaba la aplicación de la soberanía provincial sobre la jurisdicción nacional apelando a una zona de incertidumbre acerca de la continuidad de la provincia por debajo del lecho del río. Debe considerarse también la simpatía que despertaba en un amplio conjunto de la sociedad la épica de un túnel y el discurso que apelaba a la identidad provincial contra el centralismo "porteño". 
Salvar el obstáculo jurisdiccional quedaba hacerlo con el del financiamiento. La imposibilidad de endeudamiento provincial sin la venía del poder central llevaba a aplicar creativas alternativas que pudieran considerarse "recursos propios"; las rentas provinciales y la siempre coactiva coparticipación federal no podían por sí mismas financiar semejante obra. Además, la política económica nacional complicaba más las cosas con una depreciación del valor de la moneda del 134\% y una inflación del 201\% entre la adjudicación de las obras y su inauguración. No conocemos el impacto de los montos recaudados a los gravámenes a los espectáculos públicos que consideramos importantes a nivel simbólico, pero el argumento que sustentaba el proyecto y que animaba las inversiones privadas en él eran los volúmenes de tráfico potenciales que redundarían en una renta en peajes al ser el único vínculo carretero de momento entre la Megapotamia y el resto del país.

El proceso de afectación de recursos constituyó un arbitraje político entre los intereses de los diferentes actores más que un ejercicio técnico de optimización de costos. El Estado nacional, una vez echadas a andar las obras por parte de los Estados subnacionales, aunque con reticencias se vio compelido a continuarlas para no "sumergir millones de pesos en el río", fueran de las obras ejecutadas, de la tecnología comprada, de los compromisos económicos generados y de la recisión de los contratos por lucros cesantes. El Estado nacional había perdido la batalla, y como ocurre con los actores que temen haber perdido el juego directo en lo que respecta al contenido sustancial del acto de implementación, a través de una intervención sobre los contenidos institucionales del mismo, buscaron reservarse una posición clave al interior de las estructuras de vigilancia, incorporándose a la administración del túnel. El argumento del peaje fue esgrimido y la opción túnel fue vista como factible por el propio Ministerio de Obras Públicas de la Nación en el informe solicitado en 1954.

Finalmente, ante la recurrente cooptación de los gobiernos provinciales por parte de los gobiernos nacionales en Argentina, bueno es recordar la osadía de Carlos Sylvestre Begnis y Raúl Lucio Uranga. 


\section{Q Bibliografia}

» AAC (1970) El Túnel Subfluvial «Hernandarias». Carreteras, XV(53), pp.20-31.

» AAC (1960) Los caminos en el Congreso. Noticias camineras, $6(65$ a 67), p.25.

» AGUILAR VILLANUEVA, Luis (1994) Hacia una disciplina de las políticas públicas. Perfiles Latinoamericanos, 3, pp.7-16.

» ALVAREZ, Mario (1955) Nueva ruta terrestre - fluvial entre Santa Fe y Paraná. Carreteras, I(3), p.84.

" ALVAREZ, Mario (1957) Un problema argentino: Las comunicaciones con la Mesopotamia. Carreteras, III (10), pp.17-23.

» ASOCIACIÓN DE INGENIEROS DE SANTA FE (1961) A las comunicaciones entre Santa Fe y Paraná refiérese una entidad. El Litoral, p.4.

»BASUALDO, Eduardo (2006) Estudios de historia económica argentina. Desde mediados del siglo XX hasta la actualidad, Buenos Aires: Siglo XXI.

»BEGNIS, Silvestre y URANGA, Raul (1960) Tratado interprovincial sobre construcción del túnel subfluvial entre Santa Fe y Paraná, Santa Fe.

»BELL, Michael y PAVITT, Keith (1995) The Development of Technological Capabilities. En I.ul Haque, ed. Trade, Technology, and International Competitiveness. Washington: The World Bank.

»BOLSA DE COMERCIO DE CÓRDOBA (2004) Entre Ríos en la integración con los estados del sur de Brasil y Uruguay. En El balance de la economía argentina. Asia y el corredor bioceánico central. Córdoba: BCC. Available at: http://bolsacba.com. ar/buscador $/ \mathrm{p}=1827$.

" CARDOSO, Fernando y FALETTO, Eduardo (2002) Dependencia y desarrollo en América Latina: ensayo de interpretación sociológica, Buenos Aires: Siglo XXI.

» DE CARLI, Leonardo (1960) La contratación de las obras publicas. Carreteras, $\mathrm{VI}(20)$, p.4.12.

»Castellani, Ana (2009) Estado, empresas y empresarios: la construcción de ámbitos privilegiados de acumulación entre 1966 y 1989, Buenos Aires: Prometeo Libros.

»CASTELLANI, Ana (2002) La gestión estatal durante los regímenes políticos burocrático-autoritarios. El caso argentino entre 1967 y 1969. Sociohistórica, 1112, pp.35-68.

» DIFRIEDI, Héctor (1968) Panorama regional. En: Raul Leviller, ed. Historia argentina: Planeada y dirigida I. Buenos Aires: Plaza \& Janes, pp. 5-68.

»FERRER, Aldo y Marcelo ROUGIER (2010) La historia de Zárate-Brazo Largo: Las dos caras del Estado argentino, Buenos Aires: FCE.

» FRIEDBERG, Erhard (1993) Le pouvoir et la règle. Dynamiques de l'action organisée, París: Le Seuil (Sociologie).

» JONES, Charles (1977) An Introduction to the Study of Public Policy, Monterey: Duxbury Press.

» KNOEPFEL, Peter et al. (1987) Comparing environmental policies: different styles, similar content. Comparative policy research: learning from experience, pp.171-185. 
» KUCHEN, Ernest (2005) Tunnel subfluvial «R. Uranga- C. Sylvestre Begnis». Operación y mantenimiento, Paraná.

" KUTZ, Robert (1997) Canhões e Capitalismo. A revolução militar como origem da modernidade. Folha de São Paulo.

» MATEO, José (2016) Un puente hasta el túnel entre Santa Fe y Paraná. Los intentos de conexión carretera de la mesopotamia argentina hasta su instalación definitiva en la agenda de las políticas públicas (1911-1960). En A. A. Nieto \& G. Yurkievich, eds. Los Espacios portuarios. Mar del Plata: Agencia Nacional de Promoción Científica.

» MENDIAZ, María Graciela (2007) El Estado y las políticas públicas: las visiones desde el Neoinstitucionalismo, UNR.

» MENY, Yves, THOENING, Jean Claude (1992) Las políticas públicas, Barcelona: Ariel.

» MARTIN DE MOUSSY, Victor (1864) Description géographique et statistique de la Confédération Argentine. París: Librairie de Firmin Didot Fréres, Description des provinciem. pp. 1-86.

» MÜLLER, L., SHMITD, C. y PARERA, C., (2013) Túnel Subfluvial Hernandarias (Uranga-Sylvestre Begnis). Arquitectura, tecnología y proyecto: obras públicas e infraestructura territorial en Argentina (1955-1971). PICT Arquitectura 2013. Available at: http://www.fadu.unl.edu.ar/pictarquitectura2013/2016/10/17/ tunel-subfluvial-hernandarias-uranga-sylvestre-begnis/.

» MUSICH, Walter (2015) Inauguración de las obras del Puerto Nuevo de Paraná en 1904. Recuperando el acontecimiento desde la historia cultural urbana. En M. B. et al. CARPIO, ed. Actas del XXXIV Encuentro de Geohistoria Regional. Resistencia: Instituto de Investigaciones Geohistóricas, pp. 615-623.

" NIOSI, Jorge (1974) Los empresarios y el estado argentino (1955-1969), Buenos Aires: Siglo XXI.

" OSZLAK, Oscar (2014) Políticas públicas y capacidades estatales. Forjando, 3(5). Available at: https://www.bancoprovincia.com.ar/Jauretche/revista-forjando/51.

» REFFINO, Juan Carlos (1969) Túnel subfluvial Paraná Santa Fe. Una decisión regional para la integración nacional. Revista de Economía. Asociación de Economistas Argentinos (AEA), 1(3), pp.93-104.

»REGGINI, Héctor (2012) Los caminos de la palabra: las telecomunicaciones de Morse a Internet, Buenos Aires: Galápago.

» RETAMAR, C. M. et al. (2016) Túnel subfluvial Uranga-Silvestre Begnis: su medición como activo del patrimonio público y su impacto en la sociedad, Paraná.

» SABATIER, Paul (1988) An advocacy coalition framework of policy change and the role of policy-oriented learning therein. Policy Sciences, 21, pp.129-168.

» SANCHEZ GIJON, Antonio (1990) Integración en la Cuenca del Plata, Madrid: Cultura Hispánica/AECl.

"SCHMIT, Roberto (2004) Ruina y resurrección en tiempos de guerra: sociedad, economía y poder en el Oriente entrerriano posrevolucionario, 1810-1852, Buenos Aires: Prometeo Libros.

"SCHIMT, Roberto y DJENDEREDJIAN, Julio (2008) Avances y límites de la expansión agraria argentina: crecimiento económico y distribución de la riqueza rural en Entre Ríos (1860-1892). Revista de Investigaciones en Historia Económica, 11, pp.75-106. 
» SCHULTE, Ernesto (1959) La Mesopotamia argentina. Sus comunicaciones, reducción de su trocha ferroviaria media a trocha angosta, cruces del río Paraná y del río Uruguay, túnel Paraná-Santa Fe y comercio exterior. Carreteras, $\mathrm{V}(19), \mathrm{pp} .39-46$.

» SUBIRATS, Joan (2008) Análisis y gestión de políticas públicas, Barcelona: Ariel.

»SUNKEL, Oscar (2007) En busca del desarrollo perdido. En G. Vidal \& A. Guillén R., eds. Repensar la teoría del desarrollo en un contexto de globalización. México D.F.: CLACSO, Consejo Latinoamericano de Ciencias Sociales, pp. 469-488.

»VITELLI, Guillermo (1978) Cambio tecnológico, estructura de mercado y ocupación en la industria de la construcción argentina, Buenos Aires: CEPAL-BID.

\section{José Antonio Mateo Oviedo / jamateo@fceco.uner.edu.ar}

Doctor en Historia por la Universidad Pompeu Fabra (Barcelona, España), Magister en Historia por la Universidad Internacional de Andalucía, (Huelva, España) y Licenciado en Historia por la UNICEN (Tandil, Argentina). Es Profesor de la UNER (Paraná, Argentina), Investigador Independiente del CONICET (Argentina) y su lugar de trabajo es el Instituto INES.

\section{Maximiliano Camarda / maximilianocamarda@hotmail.com}

Doctor en Historia por la UNLP (La Plata, Argentina), Magister en Historia, Licenciado en Historia y Profesor en Historia por la UNMDP (Mar del Plata, Argentina). Es Becario postdoctoral en el Consejo Nacional de Investigaciones Científicas y Técnicas (Argentina) y su lugar de trabajo es el Instituto de doble dependencia, CONICETUNER, INES (Instituto de Estudios Sociales). 